\title{
Implementing Inclusive Education in Cameroon: Evidence from the Cameroon Baptist Convention Health Board
}

\author{
Louis Mbibeh $^{1, *}$ \\ ${ }^{1}$ The University of Yaoundé I, Cameroon \\ * Correspondence: P O Box 755 Yaoundé, Cameroon \\ Tel: 237-7503-6071 E-mail: mbibeh16@yahoo.com
}

Received: December 9, 2012 Accepted: January 10, 2013 Published: February 19, 2013

doi:10.5296/ije.v5i1.3279 URL: http://dx.doi.org/10.5296/ije.v5i1.3279

\begin{abstract}
This article examines the implementation of inclusive education (IE) in Cameroon. Evidence in support of the practice in Cameroon is extrapolated from the activities of the SEEPD (socio-economic empowerment of persons with disabilities) program of the CBCHB (Cameroon Baptist Convention Health Board). After establishing a number of shortcomings in terms of policy, the paper underlines that there are a plethora of legal instruments both national and international backing the implementation of inclusive education in Cameroon. An examination of IE models both in the western world and in Africa leaves the conclusion that Cameroon can draw from some of the underpinning principles in these areas yet would develop its own model based on work already being done by the SEEPD program in order to suit the social context. The paper thus proposes such a model for Cameroon. The challenges of implementing IE such as attitudes, policy, infrastructure, curriculum, and teaching learning material are considered surmountable especially if attitudes of teachers begin to change. While recognising that it takes time, commitment and effort for IE to be successful and above all sustainable, the paper proposes that instead of waiting in-fine for government policy or intervention, there is need to set the pace for IE in Cameroon using the immediate resources available rather than allow thousands to lose their human and inalienable right to education.
\end{abstract}

Keywords: inclusive education; impairment; attitudes; challenges; policy 


\section{Introduction}

One of the peculiarities of the human being is the ability to transmit knowledge from one generation to the other. That is why in the assessment of knowledge, a comparison is always made between previous and recent practice. Politicians will agree with me that the education ministries constitute one of the sectors with substantial budgetary allocations. This underscores the centrality of education to the general essence of human existence. It is therefore not an exaggeration to posit that denying someone the right to education in whatever way is a tantamount to terminating such a person's existence. This explains why a lot of policy is often developed, revised and reviewed to ensure the achievement of this goal. However, the insistence on human rights (Note 1) and especially Education For All(Note 2) aroused curiosity amongst researchers in the field. The implication was that education had not been for all. This explains the burning need for education policy that was going to involve everyone; hence the coming into the limelight of inclusive education.

Despite the enormity of literature and implementation policy developed so far the world over; Cameroon seems to have been exempted from this wind of change. Though efforts such as the 2003 laws making basic education free and compulsory for all Cameroonians have been made, there is no pause to think about learners with disabilities. It is worth noting that efforts towards educating these learners in Cameroon have been made solely by nongovernmental organisations. Such education has been in purely specialised schools (schools for the deaf and schools for the blind are found in many regions in the country). The Cameroon Baptist Convention (later CBC), owners of a number of such schools became pioneers in advocating for the implementation of inclusive education in Cameroon. It is within this caveat that this paper while raising the question, examines in detail the $\mathrm{CBC}$ experience in implementing inclusive education before proposing strategies that would ensure a complete move from policy to practice within the realms of inclusive education in Cameroon.

\section{Inclusion: Policy or Practice?}

The term inclusion has been preponderant in the literature on education from the latter part of the $20^{\text {th }}$ to the $21^{\text {st }}$ century. From a linguistic perspective, the term is derived from the verb to include which means "to have as a component part, to enclose within, to place in a general category aggregate" Websters (2010). The last dimension; that is, placing in a general category, very much ties with inclusive practice in education. Inclusion could therefore be conceptualised as placing in a general category aggregate. In which case, inclusive education would mean placing every stakeholder especially learners, within a general category without distinction.(distinction here regarded in terms of learner challenges) It should be recalled that though inclusion is essentially rooted on the principle above, its practice is diversified as observed in the definitions below.

Hooker (2007:4) views inclusion in terms of a diversity of needs and believes it is the process of addressing and responding to the diversity of such needs. In which case, inclusive education (later IE) would offer strategies for "reaching disabled children and adults and other marginalised or at risk groups" and "getting children into and through school by developing schools that are responsive to the actual diverse needs of the community. (Hooker 
ibid)

According to Windyz (2005:3) the term could be well understood if we reflect on its antonym 'exclusion' where questions like who is excluded will be involved. Within the Brazilian context, she identifies various social groups that are at risk of exclusion including the poor, those with disabilities, the black child, children with terminal diseases (AIDS, cancer) and thus defines inclusion as "a process of identification and removal of barriers that prevent any pupil at risk of exclusion from accessing the curriculum content." In practical terms, inclusion would mean "...building a school for all, a school that accepts, respects and cherishes diversity while at the same time considering the individual background of every member of the school community" (Windyz Ibid:3) In the same light, Agbenyega (2007:1) while confirming that IE is "full inclusion of children with diverse abilities in all aspects of schooling" in line with Loreman, Deppeler and Harvery (2005:2) emphasise that the Ghanaian experience outlined in the FCUBE policy is not that of movement and provision of education to learners with disabilities but that of increasing access, retention and participation of all children of school going age.

A number of researchers agree that IE is both a policy/philosophy and above all a practice (Bryant Smith 2008, Lipsky and Gartner 1997, Rogers 1993, Salend 2001).Fakolade et al (2009:3) believe the practice anchors on the notion that "every child should be an equally valued member of the school culture". The advantage as the authors insist is that "CWD benefit from learning in a regular classroom while their peers without disability gain from being exposed to children with diverse characteristics, talents and temperaments". It would be an exaggeration to think that in the $21^{\text {st }}$ century there are still countries without legislation on human rights. Of course the basic human rights include the right to education and even in the Muslim world where such rights had been restricted; the tides are gradually and completely changing. Evaluating the legislation of most developing countries, even where the term inclusion is not mentioned, laws related to education (for example in Cameroon) do not talk of exclusion. Despite the ratification of a number of international conventions and national laws to support IE in Cameroon, (discussed later in the work) no concrete actions are taken by the state to implement such conventions. Though policy is of primordial importance, IE is not just about policy but more about practice. The impact to the community is felt more when policy becomes visible through practice.

\section{The Practice of IE around the World}

IE apart from being a philosophy as discussed earlier is above all a practice. In fact, stakeholders in IE would not love to see inclusion simply as a philosophy given that the raison d'être is its practical implementation and the burning desire to see habits changing. Within this perspective, one will not need to be told but will feel the impact of IE where such is practised. The aim of this sub-section is to examine IE practice out of the country in a bid to see the lessons that could be drawn from other countries. It should be recalled that no country has the monopoly of a 'recommended' model but that each country strives for the most feasible practices in relation to its context. 
It is true that IE models had been highly developed in the western world owing especially to the fact that they began quite earlier and have developed over time. However, with reference to previous statements made in this paper, it should be recalled that such improvements do not mean they have the best practices that must fit in all societies. The centrality of IE in the west is the primordial position given to team work. In the United Kingdom, while insisting on team work, three stages can generally be identified in the practice of IE.

1) School Action: Here all teachers are trained to teach inclusively. In which case, the basics of coping with different forms of impairments are acquired.

2) School Action Plus: Here the learners' impairment could be more challenging and will thus require a support teacher to support the learner in a mainstream classroom while the general teacher is teaching.

3) Statement: Depending on the learner's challenges, when a learner is placed on a statement, they would benefit free access to education.

In the United States, the participatory approach or team work is privileged allowing for the intervention of stakeholders of diverse abilities depending on the impairment involved. In the municipality of Sao Paolo in Brazil the model adopted here focuses rather on teacher training as a prerequisite to the implementation of IE (Windyz 2005)

In Africa, the practice of IE is relatively novel compared to the western world. IE in southern Africa though having specific diversities in different countries is generally based on a participatory approach. In Zambia, Botswana, Lesotho this approach involves intervention teams including the Head teacher, senior teacher, teacher, parents (resource parents) professionals of all sorts and social workers. In Ghana, the ministry of Education Science and sports (MOESS) in its strategic education plan running from 2003 - 2015 has adopted IE as the main policy which will inform "the future direction for special education provision in the country and which will constitute a way of achieving education for all" (Hooker 2007:2). The main objective here is to reduce the number of children with disabilities (later CWD) in special schools.

This review is absolutely far from exhaustive. Its aim is to let the reader have a sketch of the models around the world and to underscore the fact that IE essentially celebrates diversity, not only in its practices but equally in the models with the ultimate goal being a society in which everyone can live and move to the heights of their aspirations without any barriers. For IE to be effective there is need for legal backing to the practice. The next section discusses such legal instruments both in and out of Cameroon.

\section{Legal Frameworks Backing Inclusive Education in Cameroon}

Social cohesion/existence can only be meaningful when there are clear-cut principles binding societies. Human civilisation has been possible because of legislation enshrined in the very essence of human existence. On the contrary, the law of the jungle could have exterminated the human race. In the same light, for IE practice to be more meaningful, there is need for 
principles that support its existence. In Cameroon where IE to a greater extent is still at the level of sensitization, there is need to create awareness on the instruments backing this practice in the territory. Hence the paper reviews both local and international regulations, conventions and laws backing IE.

\subsection{International Backing}

The move towards IE practice is grounded in the Universal Declaration of Human Rights (1948) in which access to education for all became a fundamental and inalienable human right. The UN has taken upon itself to promote such human rights and specifically regarding education, UNESCO (one of its sectors responsible for the promotion of education, science and culture) has been engaged for the past 3 to 4 decades in the fight against educational exclusion. Article 28 of the UN convention on the Rights of the Child (1989) raises the question of special needs education insisting that it has to "form part of an overall educational strategy and indeed new social and economic policies" and above all calls for major reforms in ordinary schools. Also, Article 23, 28 and 29 of the same convention focusing on CWD stipulates that "a child with physical or mental disability should enjoy decent life and should have access to education. In order to achieve this, primary education should be made compulsory and free to all"

In the 1990s, UNESCO held a number of conferences around the world with insightful outcomes geared towards the provision of education for all children without exception. Such conferences include; the Education for All (EFA) (1990) and the Salamanca Conference (1994). The World Education Conference in Jomtien Thailand (1990) raised concerns related to education for all. Article 3 of its declaration apart from advocating a breakaway from rigid prescriptive educational systems towards flexible ones, recognised the existence of disparities, and acknowledged the vulnerability of particular groups with the inherent discrimination exerted on them in education. The declaration therefore agreed that active commitment must be made to remove this disparity and every person with disabilities "who should not suffer any discrimination in access to learning opportunities" (UNESCO 1990:5) should be provided with normal education as an integral part of the educational system. This emphasised the need for IE as against exclusive education.

After raising concerns on EFA at the 1990 conference in Thailand, the subsequent conference in Salamanca 1994 outlined practical modalities for the implementation of IE in its conference Statements and Frameworks in what has become known as the Salamanca statement or framework for action. While reiterating previous sessions, the Salamanca statement confirmed that "all children and young people of the world with individual strengths and weaknesses, with their hopes and expectations have the right to education". For this objective to be attained, the Salamanca Statement and Framework introduced the principle of inclusion which was to find expression in inclusive schools. Such schools amongst other things should "accommodate all children regardless of their physical, intellectual, social, emotional, linguistic or other conditions (and) schools have to find ways of successfully educating all children including those with serious disabilities". (UNESCO1994:6). The glaring difference between these schools and special schools would 
thus be that learners will no longer try to cope with the school curriculum etc but that schools will have to find ways of successfully educating all learners that come their way. It is therefore the education system of the country that must be adjusted to meet the needs of all learners and not the learners struggling to fit into an established fixed system of education. Article 7 asserts that the fundamental principle of an inclusive school is that all children should learn together regardless of any difficulties and/or differences. Such schools must recognise and respond to all the diverse needs of their children and ensure quality education to all through appropriate curriculum, teaching strategies and partnerships with their communities. Considering that diversity is a human endowment, Article 4 insists on a sound pedagogy from which all children would benefit. In which case, child centred pedagogy is privileged in IE as it respects the dignity in diversity of all human beings and is beneficial not only to the learners with disabilities but to all learners.

It is however disheartening that despite these international conventions to which Cameroon is signatory, there are no structures in place for the practical implementation of these conventions ratified. Is it that there are no national policies to further explain the international conventions? The proceeding discussion answers this question.

\subsection{National Policies}

It should be recalled that Cameroon is a signatory to all the international conventions and policies discussed above. This means in essence that such policies need to be applied in the country. However, in addition to this there are still national policies geared towards ensuring access to education for all including learners with challenges.

Law No 83/013 of $21^{\text {st }}$ July 1983 and its decree of application Law No 90/156 of $26^{\text {th }}$ November 1990 provides general dispositions and practical modalities for the protection of persons with disabilities. Though not mentioned in clear terms, these laws all reflect inclusive practices that are cherished the world over. For example, article 30, 5, 6 and 9 of this law states that "Families should provide their children with disabilities access to regular schools. In addition, an age waver should be granted persons with disabilities to be admitted into various educational institutions on the request of CWD and their guardians and the state should bear part of the charge by admitting them to educational institutions" SEEPD (2011:5). Article 9 of this law emphasises that building plans should comprise necessary facilities that could ease access to public buildings by persons with impairments.

With regards to practical modalities, Law No 90/156 of $26^{\text {th }}$ November 1990 chapters I and II focus specifically on education. Articles 35 and 7 state that, pupils/students with disabilities should be allowed to repeat a class two times when failure is a result of their handicap. While fixing the quotas of educational assistance in kind and cash, Article 6 insists that such aid could cover complete or partial school fee requirements. While giving subventions to schools engaged in the educations of CWD, Article 4 states that qualified personnel could be posted to these schools by the state. In which case, adolescents admitted in mainstream schools would be able to benefit from pedagogic support and follow-up by teachers. This emphasises the need for training of many more teachers so as to imbibe them with inclusive teaching strategies that could be used in an inclusive set up. 
Recently, law No 2010/002 of 13 April while reemphasising dispositions in the laws discussed previously, insists on the welfare of CWD and psychological support which according to section 17 "shall aim at strengthening the psychological capacity, developing self esteem, strengthening relationships with the living environment in order to reconcile CWD and others". This in effect is the essence of IE which in practical terms could be observed in the provision of leisure activities like sports and physical education programs in schools and university systems as stipulated by section 37 of this law. By exempting CWD from paying school fees, article 29 facilitates access to education for them. Any law without sanctions for defaulters renders reinforcement and application challenging. Section 45 of this law takes care of this insisting that punishment be levied for school officials guilty of discrimination in admitting students/pupils with impairments. Punishment for such cases could range from 3 to 6 months imprisonment and a fine of 100.000CFAFrs to 1000.000CFAFrs.

The concluding remark to be made here is that in as much as these laws may sound so good, their application is still daunting. Laws are only theory, their practice renders them visible and the dream of all stakeholders in the inclusive set up is to see the laws more in application than simply on paper. In effect, the laws should be made policy. One of the challenges of the application of these laws remains the lack of qualified personnel given that the schools of education engaged in teacher training do not provide student teachers with skills/courses in IE. Except for the Higher Teacher Training College Bambili that has initiated a course in IE for guidance councillors, there is need to move further to extend this training to classroom teachers.

\section{The Cameroonian Experience: Evidence from the CBC}

Though the term inclusion had been taking primordial positions in the educational world both in the west and in Africa, Cameroon was still to join the train. The word started loaming in the educational family in Cameroon through the Cameroon Baptist Convention Health Board (CBCHB) program SEEPD (Socio-Economic Empowerment of Persons with Disabilities). The $\mathrm{CBCHB}$ had been running programs in special education following especially the medical model with a number of special schools here and there such as; The Integrated School for the Blind in Kumbo and The School for the Deaf in Mbingo. Teachers in these schools had acquired knowledge through special seminars in and out of Cameroon and could equally train other home based teachers. A glimpse of change started lingering when children from these schools were integrated into mainstream schools and allowed to cope with mainstream teachers who had little or no knowledge about handling learners with impairments. Though integration had its own loopholes, it was at least a progressive move from special education to integrated education. A number of educated people with impairments in Cameroon today are products of this integrated approach.

It was not until 2009 that the SEEPD program reviewed its education agenda that was hitherto centred on encouraging CWD to attend school and increasing their performance in examinations, to moving these children from their specialised centres to mainstream schools, 
and not just allowing them there to survive as was the case before, but building capacity for teachers to be able to handle not only these learners with impairments but all other learners in the classroom. These were mile steps toward the birth of inclusion in Cameroon. Given that this was relatively new to a number of stakeholders in the educational family, the SEEPD program started up with sensitization geared towards changing attitudes, conceptions and perceptions about persons living with impairments from the local communities to the school milieu. Given that attitudes are a very sensitive issue in human development and changing them does not end in creating awareness, there was need for practical implementation of IE to serve as an example.

The 2010/2011 training workshops organised by the SEEPD program were aimed at building and reinforcing capacities for stakeholders in education. These workshops saw the participation of teachers from both the primary and secondary sectors of education and their respective ministries. In these workshops, reports on challenges in the field are discussed in plenary and suggestions on ameliorations and accommodations made. It should be recalled that one of the aims of these interactions is to develop a model of inclusive education that would be applicable within the realities of the Cameroonian context. The underlying objective here is to address and respond to the diversity of needs of all learners by increasing participation in learning and reducing exclusion as much as possible in education as stipulated by UNESCO (2004)

\subsection{An IE Model for Cameroon?}

To put IE on the rails, the SEEPD program has selected 14 schools (both primary and secondary) in the North West Region of Cameroon to serve as pilot schools for the setting up of a model for IE in Cameroon. Through advocacy and sensitization, principals and head teachers of the 14 schools have come to a consensus to admit CWD in their schools. Teachers from these schools are called upon to implement IE strategies in the classroom. To ensure the implementation of these strategies, a number of persons are involved. It is necessary to define the duties of such persons within the framework as they constitute what we will call a model of IE for Cameroon. Through this presentation, the model of IE practiced in Cameroon through the CBCHB will be specified. It is this model that will serve as a precursor for the implementation of IE in Cameroon. These persons whose duties are entangled in a complementary web that culminates in the practice of IE include; IE teachers, lead persons, the education advisor, IE facilitators and the program manager.

i. Inclusive education teachers: These are both primary and secondary school teachers who have received classical training in a school of education and have thereafter been grounded on IE practices and strategies in the various workshops organised by the program. Above all, such a teacher is not just ready but is in effect practically implementing the acquired skills in the classroom. Such skills are developed over time and reinforced in capacity building seminars.

ii. Lead Persons: They equally constitute primary and secondary teachers with classical training in education but who have more to that received specific and advanced training in the program on IE strategies. Such persons are called upon to essentially serve as liaison 
between;

a) Students/pupils and the school administration

b) CWDs and the SEEPD program office

c) IE teachers and the SEEPD program office

d) CWD, their parents and the school administration

Since they are found in the 14 schools, their role as coordinators of IE teachers in their respective schools is primordial. They serve as an example for their colleagues and other teachers to emulate. In this light, they organise and preside at meetings as agreed upon by members to discuss successes, challenges and the way forward. Reports of such meetings are conveyed to the SEEPD program office for scrutiny. For challenges that are beyond the competence of the lead persons, they are called upon to channel them to the education advisor of the program for possible solutions.

iii. The education advisor: The advisor ensures the practical implementation of IE by overseeing the work of IE teachers through field visits and reports from Lead Persons. She carries out research on IE strategies in the world and assesses its applicability in the Cameroonian context. Equally, she develops IE strategies and discusses them in conferences organised by the program for possible adoption. Given that IE teachers have the opportunity to think and develop new strategies while teaching, she recollects such new developments through the lead persons in the various schools, presents them in organised workshops or meetings for other IE teachers to use. She equally makes proposals to the program manager for possible consideration.

iv. IE Facilitators: These are experts in given domains including varied kinds of impairments and pedagogical issues who assist IE teachers with specific problems related to their speciality. They equally prepare and present papers in conferences and workshops organized by the program on specific impairments, learner challenges and accommodations. Such facilitators include experts in Braille, Sign Language, ICT, pedagogy etc. IE teachers are free to contact these experts at any time within the working period for specific needs. Equally, it is these experts that propose strategies and possible accommodations in their speciality to the education advisor for onward transmission to the manager of the SEEDP program.

v. The SEEPD Program Manager: Though IE is just one of the many projects of the program, it is necessary to underline here that he is the general overseer of the implementation of IE in the 14 schools under his program. Amongst other things, he receives suggestions from the field through the education advisor and examines the applicability relative to available funding. He relates the project with the international world and with the government for possible funding.

vi. The resource centres: The resource centres though not yet present in all the schools are of utmost importance in the implementation of IE. Given the need for specialized material and resources that are for the most part absent in our normal classrooms, the resource centres 
facilitate IE practice in various ways;

1) Providing IE resources for teachers and students of the school.

2) Providing IE teachers' services (within the context of IE) to teachers and students of the school.

3) Promoting action research by IE teachers in the school.

4) Helping in the exchange of experiences with different resource centres in the region.

These resource centres while helping the IE teachers and learners in general, play a double role. They could be considered pilot centres for the creation of similar resource centres by the project and as an example for the government to emulate. In which case, they facilitate the development and implementation of policy in IE at the regional and why not national level.

Though not exactly the same, the model of IE practice in Cameroon has a bearing on the practice in countries both in and out of Africa. The Brazilian model in the municipality of Sao Paulo (see Windyz 2005), the Ghanaian model (Hooker 2007) and the Nigerian model (Fakolalde et al 2009) all have some level of similarity with the pioneer model being developed in Cameroon by the CBC. Of course the Cameroonian model cannot be the same like the others given that inclusion celebrates diversity "while at the same time considering the individual backgrounds in every member..." Windyz (ibid: 3).With this model, as an example, making IE policy for education in Cameroon will be less challenging. In fact, government already has administrative and logistic structures that only need adjustments in line with this model. At a time when education has become a human right issue that must be ensured for all independent of economic or social condition, physical, racial and ethnic origins, it is high time government started re-examining its laws and making them policy.

\section{Challenges and Way Forward}

Designing a model of inclusive education for Cameroon as described in the $\mathrm{CBC}$ experience above is not a bed of roses. The pilot program has got some challenges that if redressed could go a long way to foster the development and practical implementation of IE not only in the pilot schools but in the entire country. Such difficulties stem from attitudinal through policy to the curriculum.

\subsection{Attitudes}

Attitudinal challenges are usually essential in the acquisition of any new knowledge. Gardner and Lambert (972) underline that the centrality of second language acquisition lies in attitudes which when negative is equivalent to zero acquisition, while positive attitudes are noted to have fostered learning even in adverse conditions. Notwithstanding the fact that this example is drawn from linguistics, it should be noted that the question of attitude and motivation though psychological cuts across all domains and is fundamental in new experiences. Stories abound of blacks fired in the west with the simple reason that the perpetrators did not like his victims colour. This explains why it is essential to give an 
overview of attitudinal tendencies in the implementation of IE.

It is evident that questions on attitudes are mostly statistically based given that the evaluation of such attitudes is quite challenging as this is a behavioural tendency that evolves with time. At one moment one's attitude could be positive probably influenced by a present psychological state but a moment later, such attitude changes to the opposite. Given that this study is not essentially based on attitude, and that IE is still at a childhood stage, I would like to give an overview of the general attitude to give time to IE teachers to digest what it is all about before an in depth evaluation of attitudes could be possible.

Benu (2012) observes the centrality of attitudes in IE in relation to other accommodations in these words "if infrastructural ameliorations are done, if mainstream schools are ready to admit CWD, if the necessary assistive technology is available and attitudes do not change then the implementation of IE is bound to fail". That is why the workshops organised by the SEEPD program over the past two years $(2011,2012)$ have got as major objective, the creation of awareness and above all the revamping of attitudes. If attitudes have to change it means they were not positive. Evidently, like any new experience, IE in Cameroon has to face and overcome the wrath of negative attitudes. In which case, the presentation of attitudes here will focus on two phases; attitudes upon reception and afterwards.

I have observed in the various workshops that participants' immediate reaction to IE is usually that of shock and surprise. They would continue insisting that getting CWD in mainstream classrooms is an impossibility. Having this conception, any accommodation proposed in this light by facilitators meets a lot of resistance and groaning. At one moment this could be regarded as negative, yet in another perspective it is but normal and echoes a step ahead. If we look at the stages of change presented by Benuh (2012) we could be convinced that this reaction is not as negative as such. He posits that when change is introduced, the following 6 reactions ensue; shock, anger, passive acceptance, challenge and exploration.

Within the Cameroonian context, the story is not different. For teachers who have attended the workshops, the very timid ones are at the stage of passive acceptance while a majority of them who have attended at least two of these workshops are at the exploration stage. In which case, they are interested in trying the strategies in their mainstream classrooms. The fear still remains that even in the North West Region of Cameroon, not up to $50 \%$ of the teaching staff has been introduced to IE. IE is mainly practised in the pilot schools within the SEEPD program framework. We cannot say with certainty that the 200 teachers recently introduced to IE in a two-day workshop (23th to24th august 2012) have reached the stage of exploration given that they are yet to try their experience. Though they showed a lot of enthusiasm, the general conclusion is that they left the seminar passively accepting to implement IE. The challenge is that of monitoring and reinforcement to meet their difficulties in the field. The lone education advisor for the program may not be able to accompany the lot of teachers already introduced to IE. If such seed is not nurtured they may not germinate. The challenge of motivation and attitudinal tendencies remains glaring and requires regular and continuous sensitization. This can only be possible if enough experts come into play. 


\subsection{The Challenge of Policy}

As discussed earlier, it is evident that Cameroon is signatory to a number of international and even has national conventions that protect CWD and by extension back the implementation of IE in the country. The challenge is that these conventions have not been made policy as in other African countries like Ghana, Nigeria and South Africa. The timid enthusiasm exhibited by novelist teachers introduced to IE is based on the fact that it is not dictated by the state (their employer). Though the government may be looking at financial implications of the implementation of IE; it has been proven by Hooker (2007) that IE is not as expensive as we may think. It is just a better way of providing education for all. The issue however is that making IE policy is a spontaneous act but capacity building is progressive and time consuming. If the government enacts IE as policy in Cameroon today, there will be need for capacity development before IE will be visible. Hence instead of clamouring for policy, practice should take precedence and policy will surely follow suit. Advocacy may not only be by force. If government discovers that teachers want and are already teaching inclusively, there is no way policy won't follow. It is within this line of thought that the CBC and its partners will not want to hesitate in building capacity for as many teachers as possible starting with those in the NW Region. After all, IE practices only ensure a betterment of teaching without political or discriminatory tendencies that government is poised to promote.

\subsection{Infrastructure}

The challenge of infrastructure is a perennial difficulty. In as much as humanity keeps progressing, there is always need for amelioration in infrastructure. Here we could add all material developments like assistive technology and any other structural accommodation for CWD in the educational milieu. In Cameroon, the most user friendly public buildings are only a few hospitals where we could find ramps here and there. Administrative offices not to mention personal houses are constructed without the least consideration for persons with impairments. Users of buildings in the capital city will agree with me that even persons without impairments could develop one after visiting these structures(Note 3). Changing habits in this domain is not just a matter of policy but of attitudes. In the educational milieu, little ameliorations like filling up potholes, placing CWD in fairly accessible classrooms could be a pace setter. We may not want to base on the absolute availability of user friendly buildings as a precondition for IE to commence. Some little amelioration could be done in the short term to accommodate all learners and greater ameliorations would definitely follow in the long term.

\subsection{The Curriculum}

In all countries where IE has been implemented, the challenges of the curriculum remain a daunting task. This is because most curricula were developed without any consideration for learners with impairments. It equally becomes difficult to change habits of teachers who were initially trained within the backdrop of this curriculum. This difficulty is even more visible in a country like Cameroon where IE is not yet policy. The argument is that IE though not bad in itself is regarded as counter the official programs. That is why a teacher would prefer to 'cover' their program and avoid trouble with education administrators than to stick to IE and 
be reprimanded for not living up to the exigencies of the curriculum and syllabus.

One of the difficulties is that the curriculum in Cameroon is examination oriented and success in examinations especially official examinations is a tantamount to good teaching. IE proposes the contrary and teachers find it a difficult nod to swallow. It is important to know the needs of all children and reorient the curriculum to meet these needs. Why for example will a visually impaired learner be required to trace a map with very trivial contours to determine the relief and topography of an area?(Note 4) It is easier for such a learner to trace a simple raised map with a modified objective than the one above. As highlighted by Hooker (2007:10) "assessment issues constitute one of the most significant challenges for IE/EFA". Given that "a growing body of research indicates that IE benefits both the PWD and their peers and that given the appropriate support and adapted curriculum, PWD can do as well and even better than their peers", it is necessary to reconsider modifying and adapting the curriculum to suit all learners.

\subsection{The Challenge of Training}

Training and/or capacity building is capital in the propagation of all knowledge. If we can talk of IE in Cameroon, the question is; what training capacities have been put in place to ensure the training of teachers to teach inclusively? The attitudes could be positive, the infrastructure could be user friendly, and the curriculum could be flexible enough but if there are no trained teachers to teach with an inclusive methodology, IE is bound to stagger. This highlights the centrality of training in the implementation of IE in Cameroon. As of the moment, the teachers who have acquired some training in IE practice are only found in the 14 schools under the CBCHB framework. Such training is not full-time but in terms of intensive crash courses offered to teachers who had already been trained in the traditional schools of education. This is of course plausible given that teachers who are already in the field may not be asked to go back to school. This can only be done through refresh courses as is the case with the SPEEPD program where workshops are organised each year to build and reinforce teachers' capacities.

You can bear with me that in-service training cannot be as effective as training received in the school milieu. There is therefore need for the introduction of special education or IE as the case may be in teacher training colleges where both secondary and primary school teachers upon graduation will be able to teach inclusively. One of the milestones in this venture is the Teacher Training College for special education in Santa NW Region of Cameroon. Here, special needs education teachers in the primary sector are trained to take care of CWD. Though this is equally a private initiative, there is need for government to evaluate and support such initiative. While such ventures are plausible and need to be encouraged, I still believe that the move towards IE should dissociate from special need schools to inclusive ones. In which case, I propose that all teachers in all training schools be given a module of training on IE and not that specialised schools be created to train special teachers to teach special children because there is no special world or society in which such special children will live.

In the light of the above, the Higher Teacher Training College of the University of Bamenda 
in partnership with the SEEPD program of the CBCHB has introduced a module on IE and in the words of the Vice Chancellor (interview CRTV Morning Safari August 2012) there are plans to create an independent department for special needs education. In which case, the course will not only be limited to some teachers as is the case now, but will extend to involve all student teachers in the school. This is of course a milestone and a good example for other training institutions to emulate. If this is implemented, in a space of 3 to 5 years, all teachers would have become IE teachers. Hence, attitudes will definitely change and it will not be any hideous task again for government to accept IE as policy given the available personnel.

\subsection{Teaching/Learning Material}

Parents, teachers and administrators are of the opinion that low budgetary allocations are impediments to the implementation of IE. In accordance with the different learners' needs, budgets do not cater for the purchase of materials for say learners with visual and hearing impairments like tape cassettes, headphones, Braille machines, tactile maps, large print books, sign language books etc. The reliability of basic school infrastructure to support technology is questionable. Even when resource centres are available, there is still lack of software to incorporate such assistive technology programs. Teachers who are familiar with traditional teaching/learning material are hesitant to get into diverse aids that would be accessible to learners with varying impairments in a mainstream classroom. The government of Cameroon is putting in efforts towards encouraging CWD to go to school by exempting them from paying school fees. I believe this is a laudable effort but it may solve the problem only to a limited degree. Instead, it renders the parents of such children lazy. In effect, they tend to believe that CWD are government children and the purchase of learning material is even a problem to them. Equally, the parent/teachers associations (PTA) in various schools could help in this venture but since CWD do not pay fee, they are exempted from PTA projects. So, if CWD pay fee instead, such organisations will help them without any qualms.

\subsection{Assessment and Evaluation}

Assessment and evaluation constitute one of the challenges in the implementation of IE in Cameroon. As earlier mentioned, education in Cameroon is examination oriented. This means that success is evaluated in terms of the highest score on the maximal percentage. In which case, a student with 4 on 11 subjects in the GCE Ordinary levels for example is rated lower than the one with say 6 or 7 subjects. Worse still, a learner with 3 subjects in the GCE, is considered to have failed instead of that he/she has succeeded in 3 subjects. That is why CWD can find it challenging moving from one class to the other. The ideal could have been the implementation of IE practices which would cater for such discrepancies. Here, success would be assessed in terms of the learners' abilities and not disabilities. That is; what can the learner do best at what particular level of education? It is ironical to note that though you could find a learner with so many subjects say 10 in the GCE Ordinary levels, they may not even know which of the subjects is useful to them. There is therefore need for education to focus on final goals. That is; why does this learner have to acquire this and that skill in this or that particular subject?

Within the inclusive framework, the difficulties discussed above should not be considered 
impediments that would completely bar the way for the implementation of IE. Instead, such difficulties are considered opportunities to forge ahead. Partial or permanent solutions will constitute the essence of IE practice in the country.

\section{Conclusion}

This paper set out to investigate the implementation of IE in Cameroon. After reviewing the general dispensation of education in Cameroon, the paper examined the legal instruments backing IE in the country concluding that though a number of conventions (both national and international) have been signed by the government, they are yet to be ratified and made policy. After examining IE models in both western and African countries, it was concluded in line with Hooker (2007:13) that "while there are sure key underpinning values, beliefs, and principles in IE which are based on the social model, there is no blueprint and no accepted model on the best practice". As such, an evaluation of the kind of model for the Cameroonian context was examined with insights from the experience of the SEEPD program of the CBCHB. Recognising the challenges experienced so far by this program as well as future challenges, the paper concludes that while such challenges are surmountable, it is worth nothing that it takes commitment, time and effort to make IE successful and sustainable. Given the necessity for IE to be "planned for and implemented in a participatory manner firmly based in the local culture and context and fully utilising local resources" (Stubbs 2002), it is high time all stakeholders in Cameroon came to the drawing board to design a model for IE in Cameroon. Such a model should be enrooted in the essential underpinning principles of education for all but open to the realities of the country. While waiting for this dream to hopefully come true, the $\mathrm{CBC}$ experience is a laudable initiative that needs to be encouraged. Waiting for policy or government intervention could be like waiting for Samuel Becket's goddot that may never come. 


\section{References}

Agbenyega, J. (2007). Examining teachers concerns and attitudes to inclusive education in Ghana. International Journal of whole schooling, 3(1).

Benu, E. (2012). Keynote address on Inclusive Education in a one-month training workshop for lead persons. SEEPD program of the CBCHB.

Bryant, D P., Smith, DD., \& Bryant, B R. (2008) Teaching students with special needs in inclusive classrooms. Boston, MA: Pearson Education Inc.

CRTV. (2012). Interview with the Vice Chancellor of the University of Bamenda. $13^{\text {th }}$ August 2012.

Fakolade, O A., Adeniyi, S O., \& Adeyinka, T. (2009) Attitudes of teachers towards the inclusion of special needs children in general education classrooms: the case of teachers in some selected schools in Nigeria. International Electronic Journal of elementary education, 1(3), June 2009.

Gardner, R., \& Lambert, W. (1972) Attitudes and Motivation in second language learning. Rowley MA, Newbury House Publishers.

Hooker, M. (2007). Developing a model for IE and assistive technology appropriate for teaching and learning contexts in developing countries. Global e schools and Community Initiative. Dublin, Ireland.

Lipsky, D K., \& Gartner, A. (1997). Inclusion and School Reform. Transforming America's classrooms. Baltimore MD Brooks Publishing CO.

Loreman, T., Deppler, J., \& Harvey, D. (2005). A practical guide to supporting diversity in the classroom. NSW. Allen and Union

Official Gazette of the Republic of Cameroon (2010).

Rogers, J. (1993). The inclusion revolution. Research Bulletin No 11 Bloomington IN Delta Kappars centre for Evaluation, Development and Research.

Salend, S J. (2001). Creating Inclusive classrooms: Effective and Reflective Practices for all students(Fifth Edition). New Jersey: Pearson Education Inc.

SEEPD (2011) IE seminar document on laws backing IE in Cameroon.

Sidney, I (ed) (2010). Webster Compact Dictionary of the English Language. International Encyclopaedic Edition.

Stubbs, S. (2002). Inclusive Education: where there are few resources. London Atlas Alliance.

UN. (1989). Article 28, UN convention on the rights of the child.

UNESCO (1994). The Salamanca Statement and Framework for Action on special needs education adopted by the World Conference on special needs education. Access and 
Quality (Salamanca, Spain 7-10 June 1994) Paris UNESCO.

UNESCO. (1949). Universal Declaration of Human Rights.

UNESCO. (1990). World Declaration on Education for All and Framework for Action to meet Basic Learning Difficulties. UNESCO.

UNESCO. (2004). Final Report: Regional workshop on IE: Getting all children into school and helping them learn (online) Available from UNESCO chttp://www.unescobkk.org/elib/publications/inclusive Edu (Acessed $5^{\text {th }}$ july 2012).

Windyz, B. (2005). Planning and teaching curricular content by using inclusive strategies. Inclusive and support education congress paper. Sao Paulo.

\section{Notes}

Note 1. Universal Declaration of Human Rights (1949)

Note 2. The World Conference on Education for All (1990)

Note 3. Like the ministries of secondary and higher education with more than 10 levels

Note 4. Compulsory question in Geography for the GCE Ordinary Level exams

\section{Copyright Disclaimer}

Copyright reserved by the author(s).

This article is an open-access article distributed under the terms and conditions of the Creative Commons Attribution license (http://creativecommons.org/licenses/by/3.0/). 